\title{
Sorting on skills and preferences: Tinbergen meets Sattinger
}

Citation for published version (APA):

Dupuy, A. (2011). Sorting on skills and preferences: Tinbergen meets Sattinger. Researchcentrum voor Onderwijs en Arbeidsmarkt, Faculteit der Economische Wetenschappen. ROA Research Memoranda No. 3 https://doi.org/10.26481/umaror.2011003

Document status and date:

Published: 01/01/2011

DOI:

10.26481/umaror.2011003

Document Version:

Publisher's PDF, also known as Version of record

\section{Please check the document version of this publication:}

- A submitted manuscript is the version of the article upon submission and before peer-review. There can be important differences between the submitted version and the official published version of record.

People interested in the research are advised to contact the author for the final version of the publication, or visit the DOI to the publisher's website.

- The final author version and the galley proof are versions of the publication after peer review.

- The final published version features the final layout of the paper including the volume, issue and page numbers.

Link to publication

\footnotetext{
General rights rights.

- You may freely distribute the URL identifying the publication in the public portal. please follow below link for the End User Agreement:

www.umlib.nl/taverne-license

Take down policy

If you believe that this document breaches copyright please contact us at:

repository@maastrichtuniversity.nl

providing details and we will investigate your claim.
}

Copyright and moral rights for the publications made accessible in the public portal are retained by the authors and/or other copyright owners and it is a condition of accessing publications that users recognise and abide by the legal requirements associated with these

- Users may download and print one copy of any publication from the public portal for the purpose of private study or research.

- You may not further distribute the material or use it for any profit-making activity or commercial gain

If the publication is distributed under the terms of Article $25 \mathrm{fa}$ of the Dutch Copyright Act, indicated by the "Taverne" license above, 
Maastricht University

Research Centre for Education and the Labour Market | ROA

\title{
Sorting on Skills and Preferences: Tinbergen Meets Sattinger
}

Arnaud Dupuy

\section{ROA Research Memorandum}

\author{
ROA-RM-2011/3
}

Research Centre for Education and the Labour Market Maastricht University

P.O. Box 616,6200 MD Maastricht, The Netherlands

$\mathrm{T}+31433883647 \mathrm{~F}+31433884914$

secretary-roa-sbe@maastrichtuniversity.n www.roa.nl 


\title{
Sorting on Skills and Preferences: Tinbergen Meets Sattinger
}

\author{
Arnaud Dupuy \\ ROA-RM-2011/3* \\ February 2011
}

Research Centre for Education and the Labour Market

Maastricht University

P.O. Box 616, 6200 MD Maastricht, The Netherlands

$\mathrm{T}+31433883647 \mathrm{~F}+31433884914$

secretary-roa-sbe@maastrichtuniversity.nl

www.roa.nl

\footnotetext{
* The ROA Research Memorandum Series was created in order to make research results available for discussion, before those results are submitted for publication in journals.
} 


\section{Abstract}

\section{Sorting on Skills and Preferences: Tinbergen Meets Sattinger**}

This paper proposes an assignment model where sorting occurs on attributes that are simultaneously a skill (Sattinger, 1979) and a preference (Tinbergen, 1956). The key feature of this model is that the wage function admits both jobs' and workers' attributes as arguments. Since this function is generically nonlinear (Ekeland et al., 2004), even under positive assortative matching, the correlation between the contribution of workers' attributes to wages and that of jobs' attributes can vary from -1 to 1 depending on the parameters of the model, i.e. preference, technology and the distribution of both sets of attributes. The paper discusses a closed form solution of the model, presents conditions for the nonparametric identification of compensating wage differentials and nonadditive marginal utility functions using observations from a single hedonic market and proposes a nonparametric estimator.

JEL classification: D3, J21, J23 and J31

Keywords: Hedonic models, Compensating wage differentials, Personality traits, Firms and workers fixed effects, Nonparametric Identification

Arnaud Dupuy

ROA

Maastricht University

P.O. Box 616

NL-6200 MD Maastricht

The Netherlands

a.dupuy@maastrichtuniversity.nl

** Part of this paper was written while on leave at Yale in spring 2009, I want to thank the department of economics for its hospitality. This paper benefited from discussions with Joe Altonji, Pierre Cahuc, Jeremy Fox, Alfred Galichon, Jim Heckman, Fabian Lange, Michael Sattinger and Ed Vytlacil and valuable comments from participants at the Winter meetings of the Econometric Society, 2010 and the 2010 workshop on Matching and Sorting: Theory and Applications and seminars at CPB, CREST, SUNY at Albany, YALE and in particular, Michael Jerison, Guy Laroque, Adrian Masters, George Monokroussos and Coen Teulings. 


\section{Introduction}

Recent emerging empirical literature (e.g. Borghans et al., 2008) has shown the importance of personality traits in economics and in particular for earnings (Bowles et al., 2001 and Mueller and Plug, 2006). This literature shows that earnings are related to personality traits like risk aversion or conscientiousness. One possible explanation for these wage differentials would be that personality traits are linked to preferences for certain jobs' attributes so that the correlation between personality and earnings reflects compensating wage differentials for jobs disamenities. Yet, another explanation would be that personality traits are linked to skills that enhance productivity on the job and hence lead to higher wages. For instance, the documented positive effect of conscientiousness on earnings could come about because conscientiousness enhances workers' productivity or because in equilibrium, more conscientious workers are mapped onto jobs whose attributes are associated with negative intrinsic utility (tax controller) and hence require a wage compensation.

The model presented in this paper is the first to allow sorting to occur on attributes that each could be simulatenously a skill and a preference. This assignment model is concerned with the process by which heterogenous workers, characterized by a vector of attributes $t$, are assigned to heterogenous jobs, characterized by a vector of attributes $z$. In contrast to the existing literature (see 
among others, Tinbergen, 1956, Sattinger 1979, Brown 1980, Hwang et al., 1992), ${ }^{1}$ each of workers' attributes $t$ may be both a skill and a preference and each of jobs' attributes $z$ may be both a productive attribute and a disamenity. In this type of assignment models, wages reflect two compensations that arise simultaneously, namely a compensation for the skills supplied and a compensation for jobs' disamenities. This implies that the wage function takes both workers' and jobs' attributes as arguments, i.e. $w(z, t)$. In this unified hedonic economy, an equilibrium is defined by a mapping of workers' attributes $t$ onto jobs' attributes $z$, a function say $m_{w}(z)$ or $m_{f}(t)$, together with a wage function $w(z, t)$ that depends on both workers' attributes and jobs' attributes.

This paper shows conditions under which the compensating wage differential $\partial w / \partial z$ is identified nonparametrically and proposes a nonparametric estimator. First, it is shown that the mapping function $m_{f}(t)$ is identified nonparametrically using results from Matzkin (2003). This is a generalization to the unified economy of Heckman et al.'s (2009) result obtained for the Tinbergen class of models. Following the identification of $m_{f}(t)$, a method to nonparametrically identify $\partial w / \partial z$ is proposed. This method relies on imposing shape restrictions on the utility and production functions. In general, the method requires that i) the production

\footnotetext{
${ }^{1}$ Sattinger (1977) developed a compensating wage differential model where workers differ in terms of productivity and jobs in terms of the satisfaction workers receive from working at it, both unidimensional. Workers and jobs attributes are encompassed in the definition of job satisfaction and cannot be distinguished from each other. Moreover, all jobs have similar productivity. There is no complementarity between workers skills and jobs requirements.
} 
function is additive separable in $\left(z, t_{-i}\right)$ and $t_{i}$, with $t=<t_{-i}, t_{i}>$, where the contribution of $t_{i}$ is a known differentiable function $r\left(t_{i}\right)$ and ii) $t_{i}$ is a scalar attribute influencing job satisfaction. Condition i) insures that $\partial w / \partial t_{i}\left(=r^{\prime}\left(t_{i}\right)\right)$ is known. Condition ii) insures that $z$ and hence $\partial w / \partial z$ vary with $t_{i}$. When Conditions i) and ii) are met, $\partial w / \partial z$ is identified from data in a single hedonic market as $\partial w / \partial z=\frac{d w / d t_{i}-r^{\prime}\left(t_{i}\right)}{\partial m_{f} / \partial t}$. A special case is met when $t_{i}$ is a pure preference attribute, that is, $t_{i}$ affects utility but not productivity, i.e. $r^{\prime}\left(t_{i}\right)=0$ for all $z$ and $t_{i}$. Attribute $t_{i}$ is an exclusion restriction in the equilibrium wage function $w(z, t)$ since it does not affect productivity but not in the equilibrium assignment $m_{f}(t)$ since it matters for job satisfaction.

The fact that the wage function admits both workers' and jobs' attributes as arguments has important implications for empirical applications and in particular for two noteworthy segments. First, this paper relates to the empirical literature led by Rosen (1974 and 1986), aiming at estimating compensating wage differentials $\partial w / \partial z$. Assuming, as in Tinbergen (1956), that sorting occurs on preferences only, the hedonic wage function only depends on $z$, so that data on wages and $z$, i.e. $d w / d z$, identifies $\partial w / \partial z$. However, Brown (1980) recognizes that as soon as sorting occurs on both skills and preferences, the inability to control for workers' full productivity can bias estimates of compensating wage differentials in a single cross-section and this bias is likely to be large and significant as shown in 
Hwang et al. (1992). This literature typically assumes that $t$ contains two disjoint sets: a set $t^{s}$ of attributes reflecting pure productivity and a set $t^{p}$ reflecting pure preferences. The pricing function in this model takes the form $w\left(z, t^{s}\right)$ and the bias arises as soon as part of $t^{s}$ is unobserved in the data. For this reason, this literature suggests using data sets containing rich information on $t^{s}$ or using panel data to control for workers' fixed productivity. Nevertheless, the problem is more severe in the unified model presented in this paper since each of workers' attributes can be both a skill and a preference. In this economy, wages are given by the unknown function $w(z, t)$. Even if all attributes in $t$ are observed, without further assumptions, $\partial w / \partial z$ is not identified nonparametrically since for any value of $t$, the value of $z$ is uniquely determined by the mapping function $m_{f}(t)$, i.e. we have $d w / d z=\partial w / \partial z+\partial w / \partial t \times \partial m_{w} / \partial z$. The method proposed in this paper to identify and estimate compensating wage differentials applies to a great generality of hedonic economies including those studied by Brown (1980) and Hwang et al. (1992) among others.

This discussion also relates to the literature on the identification and estimation of preference (technology respectively) parameters in hedonic models using first order conditions, i.e. Ekeland et al. (2002 and 2004) and Heckman et al. (2010). This literature has shown conditions under which nonparametric identification of additive and nonadditive marginal utility models of the Tinbergen class, where 
sorting occurs on preferences only, is possible in a single hedonic market. Their identification strategy relies on the first order condition to utility maximization and builds on results from Matzkin (2003) on nonparametric estimation of nonadditive random functions. Crucial in this setting is the assumption that the compensating wage differential $\partial w / \partial z$, the left hand side of the first order condition, is identified from data on wages, workers' attributes and jobs' attributes. In the Tinbergen class of models assumed in Ekeland et al. (2004) and Heckman et al. (2010), wages depend only on $z$ so that data on wages and $z$, i.e. $d w / d z$, identifies $\partial w / \partial z$. As argued earlier, this is not anymore the case in the unified hedonic economy. However, the paper shows how the identification results presented in Heckman et al. follow once $\frac{\partial w}{\partial z}$ is identified using the method proposed in this paper.

The second segment of the empirical literature to which the model contributes is the literature on earnings regressions using matched employer-employee data, e.g. Abowd et al. (1999). This literature shows that in an earnings regression on matched employee-employer panel data, while both workers' and firms' fixedeffects correlate positively with measures of firms' productivity, their correlation is very low or even negative. The unified hedonic model presented in this paper offers a natural explanation for this puzzle. Since sorting occurs on both skills and preferences, wages are function of both workers' attributes and jobs' attributes. However, even when sorting exhibits positive assortative matching, the model does 
not imply that the contribution of workers' attributes to wages correlates positively with that of jobs' attributes. Both the sign and magnitude of the correlation between workers' and jobs' fixed-effects will depend on the preference parameters, the technology parameters and the distribution of workers' and jobs' attributes.

For instance, suppose that a worker's utility decreases with the distance between her own skills and the level of complexity of her job, as in Tinbergen (1956), but workers' skills and jobs' complexity are complement in production, as in Sattinger (1979). From both Tinbergen (1956) and Sattinger (1979) we know that in this economy more skilled workers will be assigned to more complex jobs in equilibrium, i.e. positive assortative matching arises. From Sattinger (1979) we know that the contribution of skills to wages is increasing in skills everywhere on the support of skills. ${ }^{2}$ However, from Tinbergen (1956) we also know that the contribution of job complexity to wages is only increasing in job complexity (and hence in skills since there is positive assortative matching) in intervals of job complexity where job complexity exceeds the skills of the worker matched to that job. This means that if the distribution of skills dominates the distribution of jobs stochastically at the first order, then the contribution of job complexity to wages is decreasing in job complexity (skills) while the contribution of skills to wages is increasing in skills. In this case, the correlation between both contributions is

\footnotetext{
${ }^{2}$ It is implicitly assumed that almost all workers have positive skills and almost all jobs have positive complexity. With normal distributions this is the case when the mean of each distribution is positive and large enough relative to the variance.
} 
negative even though equilibrium exhibits positive assortative matching.

Using the unidimensional quadratic-normal example, it is shown that one can calibrate the unified hedonic model so as to generate data where the contribution of workers' attributes to wages and that of job attributes both correlate positively with firms' productivity but not with each other. Changing the distribution of attributes over time induces the type of mobility of workers across firms that is necessary to identify workers' and firms' fixed-effects in matched employeremployee panel data set. It is shown that using this strategy for the unidimensional quadratic-normal example, one can generate a panel data and estimate workers' and firms' fixed-effects that both correlate with firms' productivity but not with each other.

The remaining structure of the paper is as follows. Section 2 presents the unified model for the hedonic endowment economy. Section 3 discusses the implication of the model for the identification and estimation of compensating wage differentials in a single hedonic market as well as for the literature on firms' and workers' fixedeffects in earnings regressions using matched employer-employee data. Section 4 summarizes and concludes. 


\section{The unified hedonic endowment economy model}

\section{$2.1 \quad$ Setup}

Consider a static labor market where workers match one-to-one with firms. Let each firm be endowed with a single machine. The supply of machines is therefore assumed exogenous to the model, ${ }^{3}$ and the assumption that workers and firms match one-to-one means that to produce output each machine must be operated by one and only one worker. Let a machine be characterized by a vector of attributes denoted by $z \in \widetilde{Z} \subset \mathbb{R}^{n_{z}}$. To fix ideas, machines attributes could be the level of physical strength involved in operating the machine, the level of intellectual complexity involved, the level of noise generated by the machine, the degree of risks taken while operating the machine, etc. Let the distribution of machines be represented by a non-negative Borel measure $\widetilde{\nu}_{z}$ on $\widetilde{Z}$ with total mass $\widetilde{v}_{z}(\widetilde{Z})$.

Similarly, suppose that workers are endowed with a vector of attributes $t \in \widetilde{T} \subset$ $\mathbb{R}^{n_{t}}$. These attributes could refer to cognitive ability such as physical strength, intellectual ability but also personality traits such as conscientiousness, risk aversion etc.. Let the distribution of workers be represented by a non-negative Borel measure $\widetilde{v}_{t}$ on $\widetilde{T}$ with total mass $\widetilde{v}_{t}(\widetilde{T})$.

\footnotetext{
${ }^{3}$ The assumption that firms are endowed with a machine $z$ can be released by supposing that firms are endowed with a vector of attributes $y$ (investments capacity, managers' attributes etc.) and "produce" their machine $z$. The distribution of machines is then endogenous to the model. This case corresponds to the hedonic production economy and is dealt with in an appendix available from the author upon request. The main results of the paper remain unchanged but the mechanic of the model simplifies significantly by assuming machines are endowed.
} 
We follow Chiappori et al. (2010) and allow workers and firms to remain unmatched by augmenting the spaces of workers and firms to $Z:=\widetilde{Z} \cup\left\{\oslash_{Z}\right\}$ and $T:=\widetilde{T} \cup\left\{\oslash_{T}\right\}$ where the isolated points $\oslash_{Z}$ and $\oslash_{T}$ correspond to the fictitious partners of unmatched workers and firms respectively. The corresponding augmented measures $\nu_{z}:=\widetilde{\nu}_{z}(\widetilde{Z})+\left(\widetilde{\nu}_{t}(\widetilde{T})+1\right) \delta_{\oslash_{Z}}$ and $\nu_{t}:=\widetilde{\nu}_{t}(\widetilde{T})+\left(\widetilde{\nu}_{z}(\widetilde{Z})+1\right) \delta_{\oslash_{T}}$ are balanced and normalized to probability measures without loss of generality, i.e. $\nu_{z}(Z)=\nu_{t}(T)=1$

In contrast to Tinbergen (1956), Epple (1984), Ekeland et al. (2002 and 2004) and Heckman et al. (2010), the model does not require workers' attributes to be non productive. Let the output of each machine depend on its own attributes but also on the attributes of the worker operating this machine. Let $p(z, t)$ for $(z, t) \in \widetilde{Z} \times \widetilde{T}$ be a twice differentiable continuous function indicating the units of output produced by the pair $(z, t)$. An attribute $i$ is not a productive attribute if and only if $\frac{\partial p(z, t)}{\partial t_{i}}=0$ for all $z$ and $t$. Note that some attributes may be productive at some jobs but not at others. While skills of different types will clearly affect productivity, some preferences may also affect productivity, for instance, a risk averse person might also tend to operate a machine slower, conscientious workers may take better care of their machine, etc.. To ensure that the fictitious firm $\oslash_{Z}$ does not participate, we impose that $p\left(\oslash_{Z}, t\right)=0$ if $t=\oslash_{T}$ and $-\infty$ else.

Let $w(z, t)$ for $(z, t) \in \widetilde{Z} \times \widetilde{T}$ be a twice differentiable continuous function in- 
dicating the wage of a worker with attributes $t$ when assigned to a machine with attributes $z$ and let $r(z, t)$ for $(z, t) \in \widetilde{Z} \times \widetilde{T}$ be a twice differentiable continuous function indicating the rents of a firm owning machine with attributes $z$ when employing a worker with attributes $t$. Note that, by definition, product is exhausted so that $p(z, t)-w(z, t)=r(z, t)$.

In contrast to Sattinger (1979), the model does not require that jobs' attributes do not affect intrinsic disutility. Assume a quasilinear utility function $u(z, t)=$ $w(z, t)-j(z, t)$ for $(z, t) \in \widetilde{Z} \times \widetilde{T}$ where consumption equals wages $w(z, t)$ by assuming no unearned income. Let $j(z, t)$ be a continuous twice differentiable function capturing job dissatisfaction. For instance, with $n_{z}=n_{t}$, the function $j$ could take the specific form proposed by Tinbergen (1956), $j(z, t ; A)=\frac{1}{2}(z-t)^{\prime} A(z-t)$ where $A$ is a positive definite matrix of parameters. A job attribute $i$ does not provide intrinsic utility if and only if $\frac{\partial j(z, t)}{\partial z_{i}}=0$ for all $z$ and $t$. To ensure that the fictitious worker $\oslash_{T}$ does not participate, we impose that $j\left(z, \oslash_{T}\right)=0$ if $z=\oslash_{Z}$ and $+\infty$ else.

Finally, to allow for non participation, we further impose that $w\left(\oslash_{Z}, t\right)=$ $w\left(z, \oslash_{T}\right)=w\left(\oslash_{Z}, \oslash_{T}\right)=0$ and define $-j\left(\oslash_{Z}, t\right)$ as the reservation utility for worker $t$ and $p\left(z, \oslash_{T}\right)$ as the reservation rent for firm $z$. 


\subsection{Agents' problem and equilibrium}

Each worker chooses the machine $z \in Z$ that maximizes her utility, that is either $\oslash_{Z}$ or $\arg \max _{z \in \widetilde{Z}} w(z, t)-j(z, t)$. The first order condition to $\max _{z \in \widetilde{Z}} w(z, t)-$ $j(z, t)$ reads as:

$$
\frac{\partial w(z, t)}{\partial z}-\frac{\partial j(z, t)}{\partial z}=0
$$

Assuming that the second order condition for utility maximization, i.e. $\frac{\partial^{2} w(z, t)}{\partial z^{2}}-$ $\frac{\partial^{2} j(z, t)}{\partial z^{2}}$ is negative definite, is satisfied, the implicit function theorem applies so that there exists a demand function for machines, say $z=m_{w}(t)$, that solves Equation 1 for $z \in \widetilde{Z}$ given $j(.$,$) and w(.,$.$) . Given the wage function w(.,$.$) ,$ worker $t \in \widetilde{T}$ chooses $m_{w}(t)$ over $\oslash_{Z}$, i.e. is willing to participate, if and only if $w\left(m_{w}(t), t\right)-j\left(m_{w}(t), t\right)>-j\left(\oslash_{Z}, t\right)$.

Similarly, each firm chooses the worker $t \in T$ that maximizes her rents, that is either $\oslash_{T}$ or $\arg \max _{t \in \widetilde{T}} p(z, t)-w(z, t)$. The first order condition to $\max _{t \in \widetilde{T}} p(z, t)-$ $w(z, t)$ reads as:

$$
\frac{\partial p(z, t)}{\partial t}-\frac{\partial w(z, t)}{\partial t}=0
$$


Assuming that the second order condition for rents maximization, i.e. $\frac{\partial^{2} p(z, t)}{\partial t^{2}}-$ $\frac{\partial^{2} w(t)}{\partial t^{2}}$ is negative definite, is satisfied, the implicit function theorem applies so that there exists a demand function, say $t=m_{f}(z)$, that solves Equation 2 for $t \in \widetilde{T}$ given $p(.$,$) and w(.,.) .{ }^{4}$ Given the wage function $w(.,$.$) , firm z \in \widetilde{Z}$ chooses $m_{f}(z)$ over $\oslash_{T}$, i.e. is willing to participate, if and only if $p\left(z, m_{f}(z)\right)-w\left(z, m_{f}(z)\right)>$ $p\left(z, \oslash_{T}\right)$.

Let $\gamma(z, t)$ be a non-negative measure on $Z \times T$ that assigns workers and firms to each other. The support of $\gamma$ is the smallest closed set $\operatorname{Spt}(\gamma) \in Z \times T$ of full $\operatorname{mass}(=1)$.

Definition 1 An assignment $\gamma$ is said to be feasible if and only if $\gamma(z, t) \in$ $\Gamma\left(v_{z}, v_{t}\right)=\left\{\gamma \geq 0\right.$ on $Z \times T \mid \int_{Z} d \gamma(z, t)=v_{t}$ and $\left.\int_{T} d \gamma(z, t)=v_{z}\right\}$.

The set $\Gamma\left(v_{z}, v_{t}\right)$ of feasible assignments is therefore the set of non-negative measures whose marginals are respectively $v_{t}$ and $v_{z}$.

Definition 2 An equilibrium in this economy is a feasible assignment $\gamma(z, t) \in$ $\Gamma\left(v_{z}, v_{t}\right)$ and a wage function $w(z, t)$ so that for almost all points $(z, t) \in \operatorname{Spt}(\gamma)$, workers maximize utility and firms maximize rents.

\footnotetext{
${ }^{4}$ It is important to note that the first order conditions determine the slopes and the second order conditions restrict the curvature of the equilibrium wage function on the intervals of $t$ and $z$ for which pairs of workers and firms arise in equilibrium. However, nothing is known about the cross-partial derivative. This suggests that if there exists a solution for the wage function, this solution will not be unique. All functions satisfying the first and second order conditions but with different cross-partial derivatives will also be solutions. See Section 3.3.
} 
Note that the support of the equilibrium assignment $\gamma(z, t)$ corresponds to the implicit demand functions $m_{w}$ and $m_{f}$.

\subsection{Existence, Uniqueness and Purity}

Chiappori et al. (2010) study the properties of equilibrium in hedonic model of the Tinbergen class. These results rely on the equivalence between the hedonic model and the Monge-Kantorovich optimal transportation problem. Denoting $s(z, t)=p(z, t)-j(z, t)$ the surplus of a pair $(z, t)$, the primal program of the Monge-Kantorovich transportation problem reads as $\max _{\gamma} \int_{Z \times T} s(z, t) d \gamma(z, t)$ such that $\gamma \in \Gamma\left(v_{z}, v_{t}\right)$. The dual program reads as $\min _{(U, V)} \int_{Z} V(z) d v_{z}+\int_{T} U(t) d v_{t}$ such that $V(z)+U(t) \geq s(z, t) \forall(z, t) \in Z \times T$, where $U(t)$ and $V(z)$ can be seen as the payoffs of worker $t$ and firm $z$ respectively.

Note that all that matters in the Monge-Kantorovich problem are the properties of the surplus function $s(z, t)$ and the measures $v_{t}$ and $v_{z}$. How this surplus is formed $(i . e . s(z, t)=p(z)-j(z, t)$ in the Tinbergen class or $s(z, t)=p(z, t)-j(z, t)$ in the unified class) and whether the transfer is $w(z)$ or $w(z, t)$ respectively does not matter. This means that from the perspective of the primal and dual program, whether one considers the Tinbergen class or the unified class of models is irrelevant. Nevertheless, one should bear in mind that this distinction is fundamental in the identification of how the surplus is built up, i.e. productivity and preferences, 
see section 3 of this paper.

Under the assumption that the surplus function is continuous, Theorem 1 in Chiappori (2010) applies so that an equilibrium assignment $\gamma$ exists in the unified hedonic model and there is duality. Moreover, if the surplus function also satisfies the subtwist condition defined in Definition 6 in Chiappori et al., then their Theorem 3 applies and there is a unique solution for $\gamma$. If the surplus function satisfies the stronger Twisted-buyer condition defined in Definition 5 in Chiappori et al. 2010, then their Theorem 2 applies, so that the unique solution for $\gamma$ is pure.

The proof of the existence of an equilibrium hedonic price function proposed by Chiappori et al. (2010) essentially follows from the existence of an equilibrium assignment and duality. Since Chiappori et al. (2010) focussed on the Tinbergen class of hedonic models $w(z, t)=w(z)$, a formal proof in the case of the unified economy with $w(z, t)$ is proposed in Appendix 1.

Note however that the solution for $w(.,$.$) is not unique. To see this, let \widehat{m}_{w}(t)$ and $\widehat{m}_{f}(z)$ be the solutions to the implicit demand for machines and workers. Let $\widehat{w}(z, t)$ be a solution for $w(z, t)$. The FOCs yield:

$$
\begin{aligned}
& \frac{\partial p\left(z, \widehat{m}_{f}(z)\right)}{\partial t}-\frac{\partial \widehat{w}\left(z, \widehat{m}_{f}(z)\right)}{\partial t}=0 \\
& \frac{\partial \widehat{w}\left(\widehat{m}_{w}(t), t\right)}{\partial z}-\frac{\partial j\left(\widehat{m}_{w}(t), t\right)}{\partial z}=0
\end{aligned}
$$


Totally differentiating the FOCs with respect to $z$ and $t$ respectively and rearranging yields (dropping the arguments of all functions for notational convenience):

$$
\begin{aligned}
\frac{\partial \widehat{m}_{f}}{\partial z} & =\left(\frac{\partial^{2} p}{\partial t^{2}}-\frac{\partial^{2} \widehat{w}}{\partial t^{2}}\right)^{-1}\left(\frac{\partial^{2} \widehat{w}}{\partial z \partial t}-\frac{\partial^{2} p}{\partial z \partial t}\right) \\
\frac{\partial \widehat{m}_{w}}{\partial t} & =\left(\frac{\partial^{2} \widehat{w}}{\partial z^{2}}-\frac{\partial^{2} j}{\partial z^{2}}\right)^{-1}\left(\frac{\partial^{2} j}{\partial z \partial t}-\frac{\partial^{2} \widehat{w}}{\partial z \partial t}\right)
\end{aligned}
$$

since $\frac{\partial^{2} p}{\partial t^{2}}-\frac{\partial^{2} \widehat{w}}{\partial t^{2}}$ and $\frac{\partial^{2} \widehat{w}}{\partial z^{2}}-\frac{\partial^{2} j}{\partial z^{2}}$ are negative definite hence invertible from the SOCs.

It is easy to show that for all $(z, t) \in \widetilde{Z} \times \widetilde{T}$, one could change the values of $\frac{\partial^{2} \widehat{w}}{\partial z \partial t}, \frac{\partial^{2} \widehat{w}}{\partial t^{2}}$ and $\frac{\partial^{2} \widehat{w}}{\partial z^{2}}$ in such a way that the right hand sides of Equation 3 and 4 remain unchanged and the SOCs are still satisfied. This means that even when $\widehat{m}_{f}$ and $\widehat{m}_{f}$ are unique, the solution for the wage function is not unique.

This result is of importance for the identification of $\frac{\partial w}{\partial z}$ presented below. One of the conditions for identification reads as: $\frac{\partial^{2} j}{\partial z \partial t_{i}} \neq \frac{\partial^{2} w}{\partial z \partial t_{i}}$ for some scalar $t_{i}$. Since we have multiple solutions, we can always pick one satisfying this condition.

\subsection{Quadratic-normal example}

Let $n_{z}=n_{t}=n$ and let workers' attributes be normally distributed with mean vector $\mu_{t}$ and variance-covariance matrix $\Sigma_{t}$ and let $z$ be normally distributed with mean vector $\mu_{z}$ and variance-covariance matrix $\Sigma_{z}$. Suppose that, as in 
Tinbergen (1956) job dissatisfaction is defined as $j(z, t ; A)=\frac{1}{2}(z-t)^{\prime} A(z-t)$, where $A$ is a positive definite matrix of preference parameters. Suppose further that productivity is given by $p(z, t ; E)=b_{0}+b^{\prime} z+c^{\prime} t+\frac{1}{2} z^{\prime} B z+\frac{1}{2} t^{\prime} C t+t^{\prime} D z$ and where $b_{0}$ is a constant, $b$ and $c$ are vectors and $B, C$ and $D$ are matrices of parameters. The parameters contained in $D$ indicate the extent to which the attributes of machines complement or substitute workers' attributes, i.e. $\frac{\partial p(z, t ; E)}{\partial z \partial t}=$ D.

As noted earlier by Tinbergen (1956) and Epple (1984), when attributes on both sides of the labor market are normally distributed, linear mapping functions of the form $t=\pi_{0}+\Pi_{1} z$ equilibrate supply and demand, i.e. $\mu_{t}=\pi_{0}+$ $\Pi_{1} \mu_{z}$ and $\Sigma_{t}=\Pi_{1}^{\prime} \Sigma_{z} \Pi_{1}$. The solution for $\Pi_{1}$ that maximizes total surplus is $\Sigma_{z}^{-1 / 2}\left(\Sigma_{z}^{1 / 2} \Sigma_{t} \Sigma_{z}^{1 / 2}\right)^{1 / 2} \Sigma_{z}^{-1 / 2}$ if $D+A>0$ and $\pi_{0}=\mu_{t}-\Pi_{1} \mu_{z}{ }^{5}$

It is easy to show that the first order conditions also yield linear mappings if and only if $w(z, t)$ is quadratic: say $w(z, t)=\delta_{0}+\delta^{\prime} t+\frac{1}{2} t^{\prime} \Delta t+\lambda^{\prime} z+\frac{1}{2} z^{\prime} \Lambda z .{ }^{6}$ The FOCs read as:

\footnotetext{
${ }^{5}$ Note that the power $p, p \in R, p \neq 0$, of a square matrix $A$ of size $n \times n$ is obtained as $A^{p} X=X \operatorname{diag}(\lambda)$ where $X$ is a matrix of size $n \times n$ formed of the $n$ eigenvectors of $A$ and $\lambda$ is the vector containing the corresponding eigenvalues. If in addition $A$ is symmetric, then $X$ is orthogonal so that $X^{\prime} X=X X^{\prime}=I$ and, post-multiplying both sides by $X^{\prime}$, the result simplifies to $A^{p}=X \operatorname{diag}(\lambda)^{p} X^{\prime}$. The matrix $A^{p}$ will be real if and only if all eigenvalues $\lambda$ are real and strictly positive that is if and only if $A$ is positive definite. Since $\Sigma_{t}$ and $\Sigma_{z}$ are symmetric, the above result applies to $\Sigma_{t}^{-1 / 2}$ and $\Sigma_{z}^{1 / 2}$. (See Bosch, 1987)

${ }^{6} \mathrm{We}$ choose the solution for the wage function that is additive separable in $z$ and $t$.
} 


$$
\begin{aligned}
\lambda+(\Lambda-A) z & =-A t \\
\delta-c+(\Delta-C) t & =D z
\end{aligned}
$$

These are linear functions and the reduced form solution will be of the form $t=m_{f}(z)=\pi_{0}+\Pi_{1} z$ or $z=m_{w}(t)=-\Pi_{1}^{-1} \pi_{0}+\Pi_{1}^{-1} t$. Plugging $t=\pi_{0}+\Pi_{1} z$ into 5 yields $\lambda=-A \pi_{0}$ and $\Lambda=A\left(I-\Pi_{1}\right)$. Plugging $z=-\Pi_{1}^{-1} \pi_{0}+\Pi_{1}^{-1} t$ into Equation 6 yields $\delta=c-D \Pi_{1}^{-1} \pi_{0}$ and $\Delta=C+D \Pi_{1}^{-1}$.

To illustrate the model, the closed form solution of the unidimensional quadraticnormal model is programmed in Mathematica. For a given set of parameters, this program illustrates the equilibrium with a panel of three graphics: 1) the equilibrium mapping function in the $(z, t)$ plan, 2) the equilibrium compensation for skills and the equilibrium compensation for jobs disamenities and 3) the distribution of workers' and jobs' attributes. The command Manipulate enables the user to visualize instantaneously the impact of changing structural parameters of the model on the equilibrium through these three graphics. ${ }^{7}$ As an example, Figure 4 was generated for $\Sigma_{z}=1, \Sigma_{t}=4, \mu_{z}=1, \mu_{t}=0$, and $c=10, C=-1, D=3$ and $A=3$.

\footnotetext{
${ }^{7}$ This program is available from the author upon request.
} 


\section{Implications for empirical applications}

\subsection{Identification and estimation of compensating wage differentials in a single hedonic market}

\subsubsection{Identification}

Since the seminal work by Rosen (1974), the traditional approach to estimate preference parameters, the function $j(z, t),{ }^{8}$ has consisted of two steps. In the first step, using market data on wages and jobs' attributes, one estimates the wage function applying the functional form that fits best the data. In the second step, one uses the first order condition in Equation 1 together with the compensating wage differential derived from the first step, i.e. $\frac{d w(z)}{d z}$, to recover preference estimates of $j(z, t)$.

Early literature by Brown and Rosen (1982), Epple (1987), Bartik (1987) and Kahn and Lang (1988) has argued that $j(z, t)$ cannot be identified in a single hedonic market unless an arbitrary nonlinear marginal utility is assumed. Recently, Ekeland et al. (2002 and 2004) have shown that nonlinearity is a generic feature of the hedonic model, not an arbitrary choice, and Ekeland et al. (2002 and 2004) and Heckman et al. (2010) have provided conditions under which nonparametric identification of additive and nonadditive hedonic models of the Tinbergen class

\footnotetext{
${ }^{8}$ All techniques below apply also to the estimation of productivity parameters by symmetry.
} 
is possible in a single hedonic market.

These conditions build on results from Matzkin (2003) on nonparametric estimation of additive and nonadditive random functions. All the results from Ekeland et al. and Heckman et al. crucially depend on the assumption that $\frac{d w}{d z}$ identifies $\frac{\partial w}{\partial z}$. In the Tinbergen class of models, where wages depend only on $z$, identification of $\frac{\partial w}{\partial z}$ follows by assumption, $\frac{d w}{d z}=\frac{\partial w}{\partial z}$. However, in the unified economy, wages are given by the unknown function $w(z, t)$ so that $\frac{d w}{d z}=\frac{\partial w}{\partial z}+\frac{\partial w}{\partial t} t^{\prime}$. Without further assumptions, $\frac{\partial w}{\partial z}$ is not identified nonparametrically since for any value of $t$, the value of $z$ is uniquely determined through the mapping function $z=z(t)$.

The method proposed in this paper to identify $\frac{\partial w}{\partial z}$ relies on shape restrictions on the production function $p(z, t)$. Following Ekeland et al. and Heckman at al., assume that $z \in \widetilde{Z} \subset \mathbb{R}$ is a scalar and $t=<t^{o}, t^{u}>\in \widetilde{T}^{o} \times \widetilde{T}^{u}=\widetilde{T}$ where $t^{o}$ is at least a scalar but potentially a vector of observed attributes and $t^{u} \in \widetilde{T}^{u} \subset \mathbb{R}$ is an unobserved (to the econometrician) scalar attribute. Assume further that $t^{u}$ is independent of $t^{o}$. The identification method requires first an identification of the mapping function $z=m_{w}\left(t^{o}, t^{u}\right)$. Lemma 3 is a generalization of the identification proof provided in Heckman et al. (2010) to the unified model.

Lemma 3 If $\frac{\partial^{2} j\left(m_{w}\left(t^{o}, t^{u}\right), t\right)}{\partial z \partial t^{u}}-\frac{\partial^{2} w\left(m_{w}\left(t^{o}, t^{u}\right), t\right)}{\partial z \partial t^{u}}<0$ (or $\left.>0\right)$, the mapping function $z=m_{w}\left(t^{o}, t^{u}\right)$ is identified in the unified hedonic model.

Proof. See Appendix 1. 
Note that since the solution for $w(.,$.$) is not unique, we can always choose a so-$ lution so that $\frac{\partial^{2} j\left(m_{w}\left(t^{o}, t^{u}\right), t\right)}{\partial z \partial t^{u}} \neq \frac{\partial^{2} w\left(m_{w}\left(t^{o}, t^{u}\right), t\right)}{\partial z \partial t^{u}}$. Once the mapping function $m_{w}\left(t^{o}, t^{u}\right)$ is identified, we can proceed to the identification of $\frac{\partial w}{\partial z}$. The following theorem shows that imposing some shape restrictions on the production function $p(z, t)$ allows us to identify $\frac{\partial w}{\partial z}$.

Theorem 4 Let there be a scalar attribute $t_{i}^{o}$ so that $\left.i\right) \frac{\partial j\left(m_{w}\left(t^{o}, t^{u}\right), t\right)}{\partial z \partial t_{i}^{o}} \neq \frac{\partial^{2} w\left(m_{w}\left(t^{o}, t^{u}\right), t\right)}{\partial z \partial t_{i}^{o}}$ and ii) $p(z, t)=q\left(z, t_{-i}^{o}, t^{u}\right)+r\left(t_{i}^{o}\right)$ where $r($.$) is a known differentiable function.$ Then for any $\left(z, t^{o}, t^{u}\right)$, the function $\frac{\partial w}{\partial z}$ is identified.

Proof. From the first order condition to rents maximization we have:

$$
\frac{d w}{d t_{i}^{o}} \equiv \frac{\partial w}{\partial z} \frac{\partial m_{w}}{\partial t_{i}^{o}}+\frac{\partial w}{\partial t_{i}^{o}}=\frac{\partial w}{\partial z} \frac{\partial m_{w}}{\partial t_{i}^{o}}+r^{\prime}
$$

Moreover, from Lemma 3, $\frac{\partial m_{w}}{\partial t_{i}^{o}}$ is identified. Is $\frac{\partial m_{w}}{\partial t_{i}^{o}} \neq 0$ ? Consider the first order condition to utility maximization. We have $\frac{\partial w\left(m_{w}(t), t\right)}{\partial z}-\frac{\partial j\left(m_{w}(t), t ; A\right)}{\partial z}=0$. Totally differentiating with respect to $t_{i}^{o}$ and rearranging obtains:

$$
\frac{\partial m_{w}}{\partial t_{i}^{o}}=\frac{\frac{\partial^{2} j}{\partial z \partial t_{i}^{o}}-\frac{\partial^{2} w}{\partial z \partial t_{i}^{o}}}{\frac{\partial^{2} w}{\partial z^{2}}-\frac{\partial^{2} j}{\partial z^{2}}}
$$

since by assumption the second order condition to utility maximization is sat- 
isfied, i.e. $\frac{\partial^{2} w}{\partial z^{2}}-\frac{\partial^{2} j}{\partial z^{2}}<0$.

From $\frac{\partial^{2} j\left(m_{w}\left(t^{o}, t^{u}\right), t\right)}{\partial z \partial t_{i}^{o}}-\frac{\partial^{2} w\left(m_{w}\left(t^{o}, t^{u}\right), t\right)}{\partial z \partial t_{i}^{o}} \neq 0$ we have $\frac{\partial m_{w}}{\partial t_{i}^{o}} \neq 0$ and it follows that, $\frac{\partial w}{\partial z}$ is identified as:

$$
\frac{\partial w}{\partial z}=\frac{1}{\frac{\partial m_{w}}{\partial t_{i}^{o}}}\left(\frac{d w}{d t_{i}^{o}}-r^{\prime}\right)
$$

An important special case is met when $r\left(t_{i}^{o}\right)$ is a constant. This occurs when $t_{i}^{o}$ is a pure preference attribute, $\frac{\partial p(z, t)}{\partial t_{i}^{o}}=r^{\prime}\left(t_{i}^{o}\right)=0$ for all $z$ and $t_{i}^{o}$. This means that $t_{i}^{o}$ plays the role of an exclusion restriction in the wage equation. Attribute $t_{i}^{o}$ is an argument of the mapping function $z($.$) but not of w(.,$.$) . As it turns out,$ the stronger requirement for this special case (analytically speaking) seems to be more likely to be met in real data. The general analytical setting indeed requires having measures of productivity at the individual level which is rarely available. Practitioners should therefore concentrate on finding a pure preference attribute.

As for Lemma 3, note that since the solution for $w(.,$.$) is not unique, we can$ always choose a solution so that $\frac{\partial j(z, t)}{\partial z \partial t_{i}^{o}} \neq \frac{\partial^{2} w(z, t)}{\partial z \partial t_{i}^{o}}$. Hence, the first requirement of Theorem 4 is without loss of generality.

All the identification results presented in Heckman et al. (2010) follow once $\frac{\partial w}{\partial z}$ is identified. For instance, assuming that $t^{o}$ is a vector and the distribu- 
tion of $t^{u}$ is known, the identification strategy of Theorem 3.1 in Heckman et al. (2010) is to impose that $\frac{\partial j(z, t)}{\partial z}=g\left(q\left(z, t_{1}^{o}\right), t_{2}^{o}, t^{u}\right)$ where $t^{o}=\left\langle t_{1}^{o}, t_{2}^{o}\right\rangle \in$ $\widetilde{T}_{1}^{o} \times \widetilde{T}_{2}^{o}=\widetilde{T}^{o}$, for some unknown continuous function $g: \mathbb{R} \times \widetilde{T}_{2}^{o} \times \widetilde{T}^{u} \rightarrow \mathbb{R}$ and known continuous differentiable function $q: \widetilde{Z} \times \widetilde{T}_{1}^{o} \rightarrow \mathbb{R}$. Let $Q\left(t_{2}^{o}, t^{u}\right)=$ $\left\{x \in \mathbb{R} \mid\right.$ for some $\left.t_{1}^{o}, q\left(m_{w}\left(t^{o}, t^{u}\right), t_{1}^{o}\right)=x\right\}$. Let $\left(x, t_{2}^{o}, t^{u}\right)$ be such that $\left(t_{2}^{o}, t^{u}\right) \in$ $\widetilde{T}_{2}^{o} \times \widetilde{T}^{u}$ and $x \in Q\left(t_{2}^{o}, t^{u}\right)$. By the definition of $Q\left(t_{2}^{o}, t^{u}\right)$, there exists $t_{1}^{o *} \in \widetilde{T}_{1}^{o}$ such that $q\left(m_{w}\left(t_{1}^{o *}, t_{2}^{o}, t^{u}\right), t_{1}^{o *}\right)=x$. Then $g\left(x, t_{2}^{o}, t^{u}\right)=\frac{\partial w\left(m_{w}\left(t_{1}^{o *}, t_{2}^{o}, t^{u}\right),\left(t_{1}^{o *}, t_{2}^{o}, t^{u}\right)\right.}{\partial z}$ from the first order condition to utility maximization. It follows that for all $\left(z, t^{o}, t^{u}\right)$ such that $q\left(z, t_{1}^{o}\right)=x \in Q\left(t_{2}^{o}, t^{u}\right)$, we have:

$$
\begin{aligned}
\frac{\partial j(z, t)}{\partial z} & =g\left(q\left(z, t_{1}^{o}\right), t_{2}^{o}, t^{u}\right) \\
& =\frac{\partial w\left(m_{w}\left(t_{1}^{o *}, t_{2}^{o}, t^{u}\right),\left(t_{1}^{o *}, t_{2}^{o}, t^{u}\right)\right.}{\partial z}
\end{aligned}
$$

\subsubsection{Estimation}

Since the estimation results presented in Heckman et al. (2010) follow once we have estimated $\frac{\partial w}{\partial z}$, this paper focuses on the estimation of $\frac{\partial w}{\partial z}$ and refers the reader to Heckman at al. (2010) for the estimation of $j(z, t)$. To present the problem in terms of random functions, let $W, T^{o}, Z$ be the observable variables of our model and let $T^{u}$ be the unobservable variable. All variables are of dimension 1 except $T^{o}$ that has dimension of at least 1 . Let our model be $W=w\left(Z,\left(T^{o}, T^{u}\right)\right)$ where $w$ is an unknown function continuous and twice differentiable in $Z$ and $\left(T^{o}, T^{u}\right)$ 
respectively. The function $w$ is assumed to belong to the set of functions derived from the unified economy outlined above. Let $F_{T^{u}}($.$) be the distribution of T^{u}$ and let $F_{W, Z, T^{o}}\left(. ; w^{\prime}, F_{T^{u}}^{\prime}\right)$ be the joint distribution of the observable variables when $w=w^{\prime}$ and $F_{T^{u}}^{\prime}=F_{T^{u}}$. Assume that $T^{u}$ is independent of $T^{o}$. Our data consist of a sample of $N$ draws of $W, Z$ and $T^{o}$ from a single hedonic market.

To estimate $\frac{\partial w}{\partial z}$, we need first to estimate the mapping function. From the proof of Lemma 3 we know that $m_{w}\left(t^{o}, t^{u}\right)$ is strictly increasing in its last argument and since by assumption $T^{u}$ is independent of $T^{\circ}$, we can use normalization results from Matzkin (2003) estimate $m_{w}\left(t^{o}, t^{u}\right)$ from the conditional distribution of $Z$ with respect to $T^{o}$. If $F_{T^{u}}$ is known we recover $m_{w}\left(t^{o}, t^{u}\right)$ as $F_{Z \mid, T^{o}}^{-1}\left(F_{T^{u}}\left(t^{u}\right)\right)$ and if not, we normalize the mapping function so that for some $\bar{t}^{o}$ and all $t^{u}$ we have $m_{w}\left(\bar{t}^{o}, t^{u}\right)=t^{u}$ and estimate $F_{T^{u}}\left(t^{u}\right)=F_{Z \mid T^{o}=\bar{t}^{o}}\left(t^{u}\right)$ and hence $m_{w}\left(t^{o}, t^{u}\right)=F_{Z \mid T^{o}=t^{o}}^{-1}\left(F_{Z \mid T^{o}=\bar{t}^{o}}\left(t^{u}\right)\right)$. Estimates of $z$ are obtained by replacing the true distributions $F$ by their kernel estimators $\widehat{F}$ following the definitions provided in Matzkin (2003) or in Heckman et al. (2010), in the above equalities. Denote $\widehat{m}_{w}\left(t^{o}, t^{u}\right)$ the estimated mapping function. Theorem 4 suggests the following estimator $\frac{\widehat{\partial w}}{\partial z}$ of $\frac{\partial w}{\partial z}$ for any $\bar{t}_{-i}^{o}, t_{i}^{o}, \bar{t}^{u}$ :

$$
\frac{\partial w}{\partial z}=\frac{1}{\frac{\partial \hat{m}_{w}}{\partial t_{i}^{o}}}\left(\frac{d w}{d t_{i}^{o}}-r^{\prime}\right)
$$


where $\frac{d w}{d t_{i}^{o}}$ is the observed wage differential as $t_{i}^{o}$ changes and using the known function $r$ to calculate $r^{\prime}$.

\subsection{Literature on matched employer-employee data}

This model makes interesting predictions with respect to the empirical literature estimating earnings functions using matched employer-employee panel data, e.g. Abowd et al. (1999). This literature typically finds that while both workers' and firms' fixed-effects positively correlate with measures of firms' productivity, the correlation between the two components of wages is low or even negative. While Shimer's (2005) unidimensional assignment model with coordinative frictions could generate low or even negative correlation if frictions are large enough, ${ }^{9}$ the unified model presented above predicts that a frictionless economy could also be characterized by a low or negative correlation between the contribution of workers' attributes to wages and that of jobs' attributes even though both contributions positively correlate with measures of firms' productivity and sorting exhibits positive assortative matching. The key features of the unified hedonic model that makes these predictions possible are: 1) that sorting occurs on both skills and preferences and 2) the generic nonlinearity of the wage function (see Ekeland et al., 2004).

\footnotetext{
${ }^{9}$ Recent empirical literature, e.g. De Melo (2009), Eeckhout and Kircher (2010) and Lise, Meghir and Robin (2009), argues that in an economy with search frictions, the correlation between the estimated employer and worker fixed effects may be misleading.
} 
To illustrate this result, consider the unidimensional quadratic-normal unified hedonic economy, $n_{z}=n_{t}=1$. Let $t$ be the skill level of workers and let $z$ be the level of jobs' complexity. Let $A>0$ so that workers have a preference for jobs of complexity corresponding to their skills level. Let $D>0$ so that workers' skills complement jobs' complexity in production. It is further assumed that $b, c, B, C$ and $D$ are so that production increases in $t$ and in $z$ for almost all pairs $(z, t)$.

Since $A+D>0$, we have $\Pi_{1}\left(=\sqrt{\frac{\Sigma_{t}}{\Sigma_{z}}}\right)>0$, so that this economy is characterized by positive assortative matching.

The production of a firm with job $z$ when matched with worker $m_{f}(z)=\pi_{0}+$ $\Pi_{1} z$ is given by $p\left(z, m_{f}(z)\right)=$ const $_{p}+\left(b+\Pi_{1}\left(c+\pi_{0} C\right)+\pi_{0} D\right) z+\left(\frac{B}{2}+\Pi_{1}\left(\frac{C}{2} \Pi_{1}+D\right)\right) z^{2}$ where const $_{p}=b_{0}+c \pi_{0}+\frac{C}{2} \pi_{0}^{2}$. Using the solution $\lambda=-A \pi_{0}, \Lambda=A\left(I-\Pi_{1}\right)$, $\delta=c-D \Pi_{1}^{-1} \pi_{0}$ and $\Delta=C+D \Pi_{1}^{-1}$ and after some simplifications, obtains:

$$
w(z, t)=\delta_{0}+\vartheta(t)+\kappa(z)
$$

where $\vartheta(t) \equiv\left(c-D \Pi_{1}^{-1} \pi_{0}\right) t+\frac{1}{2}\left(C+D \Pi_{1}^{-1}\right) t^{2}$ is the wage contribution of workers' attributes and $\kappa(z) \equiv-\pi_{0} A z+\frac{1}{2} A\left(1-\Pi_{1}\right) z^{2}$ is the wage contribution of jobs' attributes.

Replacing $t$ by $\pi_{0}+\Pi_{1} z$, the contribution of workers' attributes to wages is given by $\vartheta\left(m_{f}(z)\right)=$ const $_{\vartheta}+\Pi_{1}\left(c+\pi_{0} C\right) z+\frac{\Pi_{1}}{2}\left(C \Pi_{1}+D\right) z^{2}{\text { where } \text { const }_{\vartheta}=}=$ 
$\pi_{0}\left(c+\frac{\pi_{0}}{2}\left(C+D \Pi_{1}^{-1}\right)\right)$.

The three measures of interest are:

$$
\begin{aligned}
p\left(z, m_{f}(z)\right) & =\text { const }_{p}+\Omega_{p} z+\Upsilon_{p} z^{2} \\
\vartheta\left(m_{f}(z)\right) & =\text { const }_{\vartheta}+\Omega_{\vartheta} z+\Upsilon_{\vartheta} z^{2} \\
\kappa(z) & =\text { const }_{\kappa}+\Omega_{\kappa} z+\Upsilon_{\kappa} z^{2}
\end{aligned}
$$

where $\Omega_{p}=b+\Pi_{1}\left(c+\pi_{0} C\right)+\pi_{0} D, \Upsilon_{p}=\frac{B}{2}+\Pi_{1}\left(\frac{C}{2} \Pi_{1}+D\right), \Omega_{\vartheta}=\Pi_{1}\left(c+\pi_{0} C\right)$, $\Upsilon_{\vartheta}=\frac{\Pi_{1}}{2}\left(C \Pi_{1}+D\right)$, const $_{\kappa}=0, \Omega_{\kappa}=-\pi_{0} A$ and $\Upsilon_{\kappa}=\frac{A}{2}\left(1-\Pi_{1}\right)$

The question arises whether we can calibrate the parameters of the model so that $\operatorname{COV}(\vartheta, p) \gg 0, \operatorname{COV}(\kappa, p) \gg 0$ and $\operatorname{COV}(\vartheta, \kappa)=0$ with the constraints that $A+D>0$ and hence $\Pi_{1}>0$. These three conditions read as:

$$
\begin{aligned}
& C O V(\vartheta, p) \gg 0 \Leftrightarrow \Omega_{p} \Omega_{\vartheta} \frac{\Sigma_{z}}{V\left(z^{2}\right)}+\left(\Upsilon_{p} \Omega_{\vartheta}+\Upsilon_{\vartheta} \Omega_{p}\right) \frac{C O V\left(z, z^{2}\right)}{V\left(z^{2}\right)}+\Upsilon_{p} \Upsilon_{\vartheta} \gg 0 \\
& \operatorname{COV}(\kappa, p) \gg 0 \Leftrightarrow \Omega_{p} \Omega_{\kappa} \frac{\Sigma_{z}}{V\left(z^{2}\right)}+\left(\Upsilon_{p} \Omega_{\kappa}+\Upsilon_{\kappa} \Omega_{p}\right) \frac{C O V\left(z, z^{2}\right)}{V\left(z^{2}\right)}+\Upsilon_{p} \Upsilon_{\kappa} \gg 0 \\
& \operatorname{COV}(\vartheta, \kappa)=0 \Leftrightarrow \Omega_{\kappa} \Omega_{\vartheta} \frac{\Sigma_{z}}{V\left(z^{2}\right)}+\left(\Upsilon_{\kappa} \Omega_{\vartheta}+\Upsilon_{\vartheta} \Omega_{\kappa}\right) \frac{C O V\left(z, z^{2}\right)}{V\left(z^{2}\right)}+\Upsilon_{\kappa} \Upsilon_{\vartheta}=0
\end{aligned}
$$

Note first that one would not be able to satisfy these three conditions if 
$\vartheta\left(m_{f}(z)\right)$ and $\kappa(z)$ were linear functions of $z$. For these conditions to be satisfied we need $\vartheta\left(m_{f}(z)\right)$ and $\kappa(z)$ to be nonlinear functions of $z$.

Note also that $C O V\left(z, z^{2}\right)$ and $V\left(z^{2}\right)$ merely depend on $\mu_{z}$ and $\Sigma_{z}$ so that these three conditions are governed by 10 free parameters, i.e. $\mu_{z}, \Sigma_{z}, b, B, c, C, D, A$, $\Pi_{1}$ (or $\Sigma_{t}$ once $\Sigma_{z}$ is given) and $\pi_{0}$ (or $\mu_{t}$ once $\mu_{z}$ and $\Pi_{1}$ are given) suggesting an infinity of solutions to the problem. However, it seems appropriate to restrict the domain of the parameters to ensure absolute advantage of workers and firms that is 1) more skilled workers are more productive in all jobs, 2) more complex jobs are more productive independently of the type of the worker. Formally these conditions read as:

$$
\begin{aligned}
\frac{\partial p(z, t ; E)}{\partial t}= & c+C t+D z>0 \text { for almost all } t \text { and } z \\
\Leftrightarrow & c>\min _{z, t}(-C t-D z) \\
& \text { and } \\
\frac{\partial p(z, t ; E)}{\partial z}= & b+B z+D t>0 \text { for almost all } t \text { and } z \\
\Leftrightarrow & b>\min _{z, t}(-B z-D t)
\end{aligned}
$$

Since $z$ and $t$ are normally distributed their support is the real line. For the conditions above to be met for almost all $t$ and $z$ would require $c$ and $b$ to be 
infinitely large. Instead, the conditions are imposed for all $t$ within 2 standard deviations from the mean and all $z$ within 2 standard deviations from the mean. Formally we impose:

$$
\begin{gathered}
c>-C\left(\mu_{t}-l \times 2 \sqrt{\Sigma_{t}}\right)-D\left(\mu_{z}-2 \sqrt{\Sigma_{z}}\right) \text { where } l=\left\{\begin{array}{c}
-1 \text { if } C<0 \\
1 \text { else }
\end{array}\right. \\
b>-B\left(\mu_{z}-m \times 2 \sqrt{\Sigma_{z}}\right)-D\left(\mu_{t}-2 \sqrt{\Sigma_{t}}\right) \text { where } m=\left\{\begin{array}{c}
-1 \text { if } B<0 \\
1 \text { else }
\end{array}\right.
\end{gathered}
$$

As it turns out, even with these additional restrictions imposed on the parameters, one can easily calibrate the model so as to generate $C O V(\vartheta, p) \gg 0$, $C O V(\kappa, p) \gg 0$ and $\operatorname{COV}(\vartheta, \kappa)=0$. For instance, the calibration reported in Table 1, shows, for a sample of 5000 firms and workers, that $C O V(\vartheta, p)=0.93$, $\operatorname{COV}(\kappa, p)=0.40$ and $\operatorname{COV}(\vartheta, \kappa)=0.04$

One can even go further and generate not just one cross section of wage data but several successive cross-sections. Provided there is enough mobility of workers across firms in the data, one would then be able to estimate firms' and workers' fixed-effects using firms' and workers' identity and wages as in Abowd et al. (1999).

The problem in hedonic models is to generate the kind of mobility necessary to identify these fixed-effects. The solution is to either let the distribution of jobs or the distribution of workers change over time. As either distribution changes 
over time, the mapping function changes (remember that $\Pi_{1}=\sqrt{\frac{\Sigma_{t}}{\Sigma_{z}}}$ and $\pi_{0}=$ $\mu_{t}-\Pi_{1} \mu_{z}$ ) which as the effect of shuffling the identity (defined by $t$ ) of the worker assigned to each firm (identity defined by $z$ ) over time.

In the following example, five successive years of data are generated for an economy of 5000 firms and 5000 workers and the parameters are calibrated as in Table 1. The required mobility is generated by successive increments of magnitude 0.05 in $\mu_{t}$, i.e. $\mu_{t}$ increases from -0.04 to 0.16 , keeping the variance of skills and the distribution of jobs constant over time. In each cross section the assignment of workers to firms is defined by $t=\pi_{0}+\Pi_{1} z$ and wages are determined as $\delta_{0}+\vartheta\left(m_{f}(z)\right)+\kappa(z)+e$ where $e$ a random error that follows a normal distribution. Note however that since the parameters of the equilibrium wage function depend on $\pi_{0}=\mu_{t}-\Pi_{1} \mu_{z}$ that varies over time, the shape of the wage function also changes over time. The wage equation in year $y$ can be re-written as:

$$
\begin{aligned}
w_{y}(z, t) & =\delta_{0 y}+\vartheta_{y}(t)+\kappa_{y}(z)+e_{y} \\
& =\delta_{0 y}+\bar{\vartheta}(t)+\bar{\kappa}(z)+\psi_{y}(t)+\chi_{y}(z)+e_{y} \\
\text { where } \psi_{y}(t) & =\vartheta_{y}(t)-\bar{\vartheta}(t) \text { and } \chi_{y}(z)=\kappa_{y}(z)-\bar{\kappa}(z)
\end{aligned}
$$

The terms $\bar{\vartheta}(t)$ and $\bar{\kappa}(z)$ are respectively the mean wage contribution of work- 
ers' attributes $t$ and the mean wage contribution of firms' attributes $z$. The workers fixed effects estimate $\bar{\vartheta}(t)$ whereas the firms fixed effects estimate $\bar{\kappa}(z)$. As is well-known in this literature, identification of workers' and firms' fixed-effects is only possible within connected groups of workers and firms (see Abowd et al., 2002). Such a group contains all the workers who ever worked for any firm in the group and all the firms at which any worker in the group were ever employed. Given the generated panel data, that contains information on wages, firms' identity and workers' identity in five successive years, workers' and firms' fixed-effects are estimated using the a2reg Stata command (see Ouazad, 2008) on the largest connected group (selected using the a2group stata command). This group contains 4706 different firms and 4706 different workers observed on average in 3.3 years.

Denote $\widehat{\vartheta}$ and $\widehat{\kappa}$ the estimated fixed-effects of workers and firms respectively. Estimation results show first that the estimated firms' and workers' fixed-effects are highly correlated with their respective true effects $(C O V(\vartheta, \widehat{\vartheta})=0.98$ and $\operatorname{COV}(\kappa, \widehat{\kappa})=0.68)$. Second, we find a negative correlation between the estimated firms' and workers' fixed-effects, i.e. $\operatorname{COV}(\widehat{\vartheta}, \widehat{\kappa})=-0.27$ (true correlation is $\operatorname{COV}(\vartheta, \kappa)=0.01)$, whereas both sets of fixed-effects correlate positively with firms' productivity, i.e. $\operatorname{COV}(\widehat{\vartheta}, p)=0.87($ where $\operatorname{COV}(\vartheta, p)=0.94)$ and $\operatorname{COV}(\widehat{\kappa}, p)=0.21($ where $C O V(\kappa, p)=0.23)$. 


\section{Conclusion}

This paper unifies the two classes of models within the sorting literature. The model nests both Tinbergen's model of sorting on job preferences and Sattinger's model of sorting on productivity. Under the assumption that all jobs' attributes lead to intrinsic disutility but workers' attributes do not affect productivity the model collapses to Tinbergen's model. Workers care about their job satisfaction but are equally productive at all jobs. This means that the wage function does not depend on workers' attributes but merely on jobs' attributes. Opposite to this, under the assumption that all workers' attributes contribute to productivity but no jobs' attributes lead to intrinsic disutility the model collapses to Sattinger's differential rents model. Workers do not care about job satisfaction, only about their wage, but workers with different attributes are unequally productive. This means that the wage function does not depend on jobs' attributes but merely on workers' attributes. In the more general case depicted in the unifying model, workers do care about job's satisfaction and productivity does depend on workers' attributes. As a result, the wage function has both workers' and jobs' attributes as arguments. An example of closed form solution is provided when productivity and job satisfaction are quadratic and attributes on both sides are normally distributed.

The model has implications for the identification and estimation of i) compensating wage differentials (see Rosen 1974 and 1987) and ii) preference (technology 
respectively) parameters in hedonic models (see Ekeland et al., 2002 and 2004, and Heckman et al., 2010). In the unified economy where sorting occurs on attributes that are simultaneously a skill and a preference, wages are given by the unknown function $w(z, t)$. Without further assumption, $\frac{\partial w}{\partial z}$ is not identified nonparametrically since for any value of $t$, the value of $z$ is uniquely determined by the mapping function $z=m_{w}(t)$. This paper first shows in Lemma 3 that the mapping function $z(t)$ is identified nonparametrically using results from Matzkin (2003). Lemma 3 generalizes Heckman et al.'s (2010) results to the unified hedonic model. Using the identification result for $m_{w}(t)$, this paper shows conditions under which $\frac{\partial w}{\partial z}$ is identified nonparametrically in Theorem 4 . These conditions impose shape restrictions on the production function $p(z, t)$. In particular, the method assumes that $p(z, t)=q\left(z, t_{-i}\right)+r\left(t_{i}\right)$ where $r($.$) is a known differentiable$ function and with $t=<t_{-i}, t_{i}>$ and where $t_{i}$ is a preference attribute, i.e. so that $\frac{\partial j(z, t)}{\partial z \partial t_{i}} \neq \frac{\partial^{2} w\left(m_{w}\left(t^{o}, t^{u}\right), t\right)}{\partial z \partial t_{i}^{o}}$. A special case is met when $t_{i}$ is a pure preference attribute, that is, $t_{i}$ affects utility but not productivity, i.e. $\frac{\partial p(z, t)}{\partial t_{i}}=0$ for all $z$ and $t_{i}$. Attribute $t_{i}$ is an exclusion restriction in $w(.,$.$) since it does not affect$ productivity but not in $m_{w}(t)$ since it matters for job satisfaction.

The model is flexible enough to allow the correlation between the contribution of workers' attributes to wages and that of jobs' attributes to vary between -1 to 1 . This correlation depends on preference parameters, technology parameters 
and the distribution of workers and jobs' attributes. The model therefore provides an explanation for Abowd et al.'s (1999) puzzling finding of a low or even negative correlation between workers' and firms' fixed-effects in wage regressions using matched employer-employee data that does not require (large) frictions (Shimer, 2005). The key features of the unified hedonic model that makes this prediction possible are: 1) that sorting occurs on both skills and preferences and 2) the generic nonlinearity of the wage function (see Ekeland et al., 2004).

\section{References}

Abowd, J., F. Creecy, and F. Kramarz (2002): “Computing Person and Firm Effects Using Linked Longitudinal Employer-Employee Data," Cornell University Working Paper.

Abowd, J., F. Kramarz, and D. Margolis (1999): "High Wage Workers and High Wage Firms," Econometrica, 67(2), 251-333.

Bartik, T. J. (1987): "Estimating Hedonic Demand Parameters with Single Market Data: The Problems Caused by Unobserved Tastes," The Review of Economics and Statistics, 69(1), 178-80.

Borghans, L., A. L. Duckworth, J. J. Heckman, and B. ter Weel (2008): "The Economics and Psychology of Personality Traits," Journal of Human Re- 
sources, 43(4).

Bosch, A. J. (1987): "Note on the Factorization of a Square Matrix Into Two Hermitian or Symmetric Matrices," SIAM Review, 29(3), 463-468.

Bowles, S., H. Gintis, and M. Osborne (2001): "The Determinants of Earnings: A Behavioral Approach," Journal of Economic Literature, 39(4), 11371176.

Brown, C. (1980): "Equalizing Differences in the Labor Market," Quarterly Journal of Economics, 94(1), 113-134.

Brown, J. N., And H. S. Rosen (1982): "On the Estimation of Structural Hedonic Price Models," Econometrica, 50(3), 765-768.

Chiappori, P.-A., R. MCCann, and L. Nesheim (2010): "Hedonic price equilibria, stable matching, and optimal transport: equivalence, topology, and uniqueness," Economic Theory, 42(2), 317-354.

De Melo, R. L. (2009): "Sorting in the Labor Market: Theory and Measurement," mimeo.

Eeckhout, J., And P. Kircher (2010): "Identifying Sorting - In Theory," Review of Economic Studies, forthcoming. 
Ekeland, I., J. J. Heckman, and L. Nesheim (2002): "Identifying Hedonic Models," American Economic Review, 92(2), 304-309.

(2004): "Identification and Estimation of Hedonic Models," Journal of Political Economy, 112(2), S60-S109.

Epple, D. (1984): "Closed Form Solutions to a Class of Hedonic Models," unpublished manuscript.

(1987): "Hedonic Prices and Implicit Markets: Estimating Demand and Supply Functions for Differentiated Products," Journal of Political Economy, $95(1), 59-80$.

Heckman, J. J., R. L. Matzkin, and L. Nesheim (2010): "Nonparametric Identification and Estimation of Nonadditive Hedonic Models," Econometrica, 78(5), 1569-1591.

Hwang, H.-S., W. R. Reed, and C. Hubbard (1992): "Compensating Wage Differentials and Unobserved Productivity," Journal of Political Economy, $100(4), 835-58$.

Kahn, S., and K. LAng (1988): "Efficient Estimation of Structural Hedonic Systems," International Economic Review, 29(1), 157-66.

Lise, J., C. Meghir, And J.-M. Robin (2009): "Matching, Sorting and Wages," mimeo. 
MATZKin, R. (2003): "Nonparametric estimation of nonadditive random functions," Econometrica, 71(5), 1339-1375.

Mueller, G., and E. Plug (2006): "Estimating the effect of personality on male and female earnings," Industrial and Labor Relations Review, 60(1), 3-22.

OuAzad, A. (2008): “A2REG: Stata module to estimate models with two fixed effects," Statistical Software Components, Boston College Department of Economics.

Rosen, S. (1974): "Hedonic Prices and Implicit Markets: Product Differentiation in Pure Competition," Journal of Political Economy, 82, 34-55.

(1987): "The theory of equalizing differences," in Handbook of Labor Economics, ed. by O. Ashenfelter, and R. Layard, vol. 1 of Handbook of Labor Economics, chap. 12, pp. 641-692. Elsevier.

Sattinger, M. (1977): "Compensating wage differences," Journal of Economic Theory, 16(2), 496-503.

(1979): "Differential Rents and the Distribution of Earnings," Oxford Economic Papers, 31(1), 60-71.

Shimer, R. (2005): "The Assignment of Workers to Jobs in an Economy with Coordination Frictions," Journal of Political Economy, 113(5), 996-1025. 
Tinbergen, J. (1956): "On the Theory of Income Distribution," Weltwirtschaftliches Archiv, 77(1), 156-75. 


\section{Appendix 1:}

Proof of the existence of an equilibrium wage function $w(z, t)$. Let $w: Z \times T \rightarrow \mathbb{R}$ satisfy:

$$
U(t)+j(z, t) \geq w(z, t) \geq p(z, t)-V(z)
$$

The left hand side of this inequality is the minimum willingness of worker $t$ to accept job $z$ while the right hand side is the maximum willingness of firm $z$ to pay for worker $t$.

Take a feasible triple $(\gamma, U, V)$ and suppose that $(U, V)$ solves the dual program so that $V(z)+U(t) \geq s(z, t)=p(z, t)-j(z, t)$. Rearranging obtains:

$$
U(t)+j(z, t) \geq p(z, t)-V(z) \text { for }(z, t) \in Z \times T
$$

Suppose also that $\gamma$ solves the primal program so that from the duality we have $\int_{Z \times T} s(z, t) d \gamma(z, t)=\int_{Z} V(z) d F_{z}(z)+\int_{T} U(t) d F_{t}(t)$. It follows that:

$$
\int_{Z \times T} s(z, t) d \gamma(z, t)=\int_{Z \times T}(V(z)+U(t)) d \gamma(z, t)
$$

since $\int_{Z} d \gamma(z, t)=v_{t}$ and $\int_{T} d \gamma(z, t)=v_{z}$. This yields $s(z, t)=V(z)+U(t)$ for $\gamma$-almost every $(z, t)$. Consider a worker $t^{*}$ that is matched with a firm $z^{*}$. We 
have $s\left(z^{*}, t^{*}\right)=V\left(z^{*}\right)+U\left(t^{*}\right)$ and hence:

$$
U\left(t^{*}\right)+j\left(z^{*}, t^{*}\right)=w\left(z^{*}, t^{*}\right)=p\left(z^{*}, t^{*}\right)-V\left(z^{*}\right)
$$

From our choice of $w(z, t)$ in Inequality 8 we have $U\left(t^{*}\right)+j\left(z, t^{*}\right) \geq w\left(z, t^{*}\right)$ for worker $t^{*}$ and $z \in Z$ and $w\left(z^{*}, t\right) \geq p\left(z^{*}, t\right)-V\left(z^{*}\right)$ for firm $z^{*}$ and all $t \in T$. Rearranging and using Equation 10 obtains:

$$
\begin{aligned}
& p\left(z^{*}, t\right)-w\left(z^{*}, t\right) \leq V\left(z^{*}\right)=p\left(z^{*}, t^{*}\right)-w\left(z^{*}, t^{*}\right) \forall t \in T \\
& w\left(z, t^{*}\right)-j\left(z, t^{*}\right) \leq U\left(t^{*}\right)=w\left(z^{*}, t^{*}\right)-j\left(z^{*}, t^{*}\right) \forall z \in Z
\end{aligned}
$$

It follows that $t^{*}$ maximizes $p\left(z^{*}, t\right)-w\left(z^{*}, t\right)$ and $z^{*}$ maximizes $w\left(z, t^{*}\right)-$ $j\left(z, t^{*}\right)$. Since the equalities in 11 and 12 hold for $\gamma$-almost every $(z, t)$ and $\gamma$ exists, there exists a solution $(\gamma, w)$ to the unified hedonic model.

Proof of Lemma 3. Consider the first order condition to utility maximization, $\frac{\partial w\left(m_{w}(t), t\right)}{\partial z}-\frac{\partial j\left(m_{w}(t), t ; A\right)}{\partial z}=0$. Totally differentiating with respect to $t^{u}$ and rearranging yields:

$$
\frac{\partial m_{w}}{\partial t^{u}}=\frac{\frac{\partial^{2} j}{\partial z \partial t^{u}}-\frac{\partial^{2} w}{\partial z \partial t^{u}}}{\frac{\partial^{2} w}{\partial z^{2}}-\frac{\partial^{2} j}{\partial z^{2}}}
$$

Using the second order condition to utility maximization, we have $\frac{\partial m_{w}}{\partial t^{u}}>0$ 
if $\frac{\partial^{2} j}{\partial z \partial t^{u}}-\frac{\partial^{2} w}{\partial z \partial t^{u}}<0$. The mapping function is strictly increasing in $t^{u}$. Therefore, $m_{w}\left(t^{o}, t^{u}\right)$ is identified using normalization results from Matzkin (2003) and assuming that $t^{o}$ and $t^{u}$ are independently distributed. 


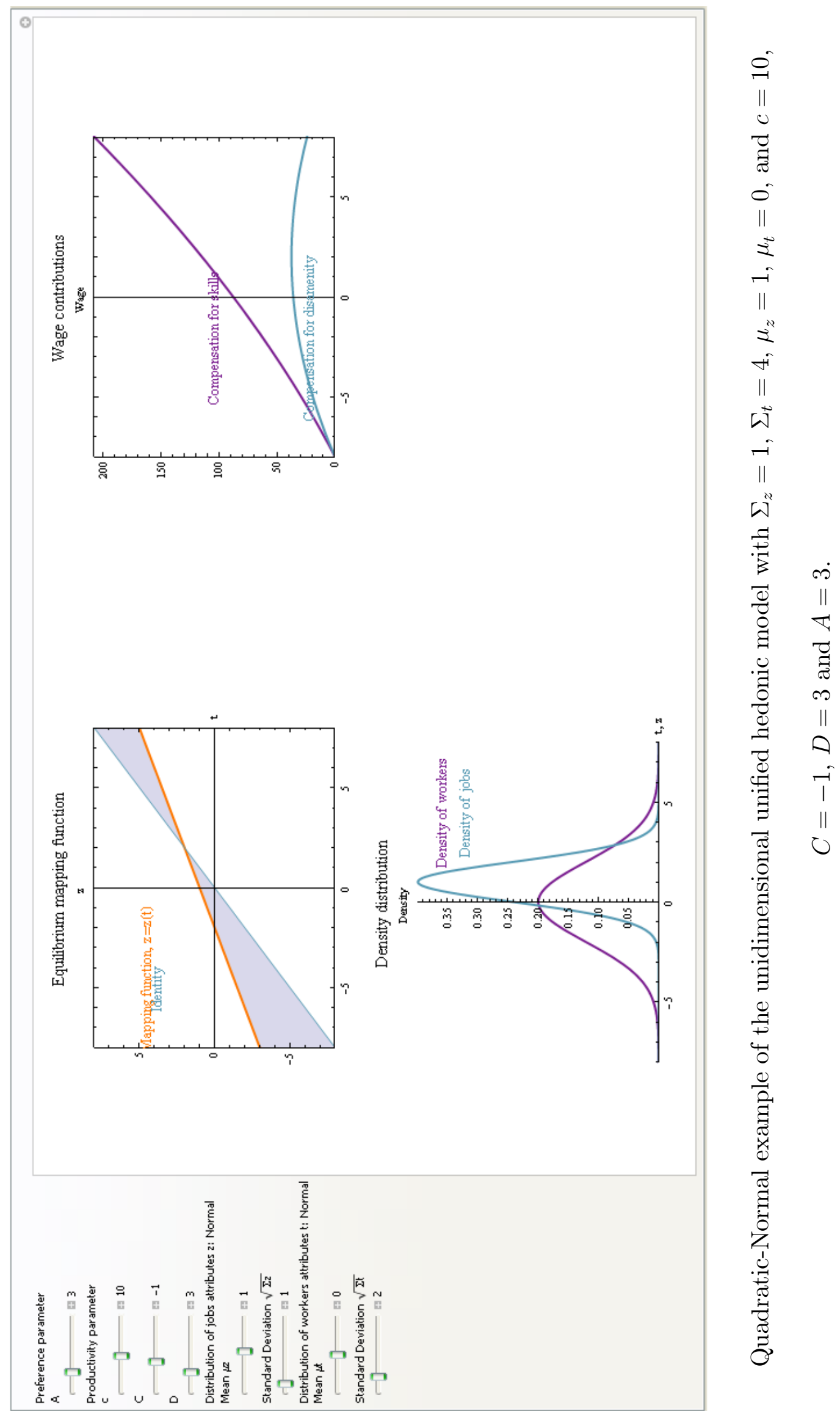




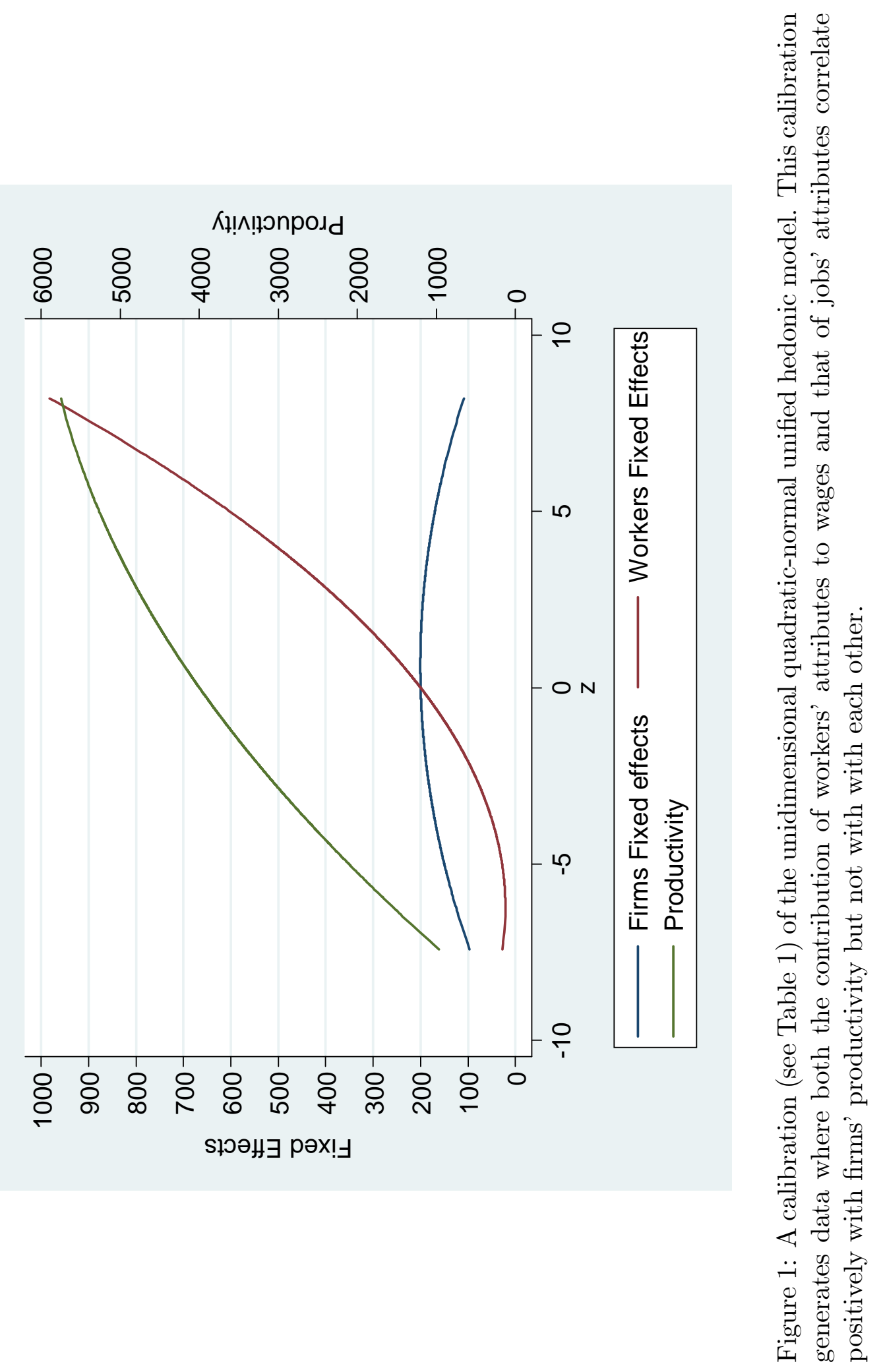


Table 1: A calibration of the unidimensional quadratic-normal unified hedonic model.

\begin{tabular}{|c|c|c|c|c|}
\hline Parameters & & $\begin{array}{r}C O V(p, \vartheta) \\
0.93\end{array}$ & $\begin{array}{r}C O V(p, \kappa) \\
0.40\end{array}$ & $\begin{array}{r}C O V(\vartheta, \kappa) \\
0.04\end{array}$ \\
\hline$A$ & 8.00 & & & \\
\hline$c$ & 40.80 & & & \\
\hline C & -1.00 & & & \\
\hline$b$ & 260.44 & & & \\
\hline$B$ & -45.44 & & & \\
\hline$D$ & 8.00 & & & \\
\hline$\Sigma_{z}$ & 5.00 & & & \\
\hline$\Pi_{1}$ & 1.40 & & & \\
\hline$=>\Sigma_{t}$ & 9.80 & & & \\
\hline$\mu_{z}$ & 0.15 & & & \\
\hline$\pi_{0}$ & -0.25 & & & \\
\hline$=>\mu_{t}$ & -0.04 & & & \\
\hline
\end{tabular}

